$04,11,13$

\title{
Зарождение алмаза из активируемой газовой фазы
}

\author{
(C) Б.В. Спицын \\ Институт фризической химии и электрохимии им. А.Н. Фрумкина РАН, \\ Москва, Россия \\ E-mail: bvspitsyn@gmail.com \\ Поступила в Редакцию 16 июля 2019 г. \\ В окончательной редакции 16 июля 2019 г. \\ Принята к публикации 25 июля 2019 г.
}

\begin{abstract}
Рассмотрено зарождение термодинамически метастабильного алмаза как в объеме активируемой газовой фазы, так и на поверхности неалмазных материалов. Обсуждаются основные факторы, вызывающие снижение поверхностной энергии образующейся алмазной фазы и уменьшение энергии активации встраивания новых частиц в формирующийся алмазный зародыш. Отмечена важность найденных экспериментально закономерностей, в частности, для получения нанокристаллических алмазных пленок субмикронной толщины.
\end{abstract}

Ключевые слова: алмаз, зарождение, активируемая газовая фаза, наноалмаз.

DOI: $10.21883 /$ FTT.2020.01.48724.55ks

\section{1. Введение}

Зарождение конденсированного состояния вещества как первоначальный этап фазового перехода I рода относится к наиболее длительно и широко изучаемым методом физики и физикохимии процессам [1-3]. Сложность этого типа явлений даже в случае исследования простейших однокомпонентных систем уступает разве только процессам абиогенного зарождения жизни на Земле. Настоящее сообщение включает рассмотрение и обсуждение некоторых из закономерностей зарождения алмаза в условиях его термодинамической метастабильности. В процессе открытия и разработки принципиально нового метода синтеза алмаза из газовой фазы [4-10] была установлена возможность не только наращивания метастабильного алмаза на одноименном затравочном кристалле, но и возникновение центров роста алмаза в объеме газовой фазы, а также зарождение алмаза на поверхности неалмазных материалов.

\section{2. Классическая теория зарождения}

Согласно теории гомогенного зарождения [11]:

$$
J=A \exp \left(-\Delta G_{a} / k T\right) \exp \left(-16 \pi \Omega^{2} \alpha^{3} / 3 k T \Delta \mu^{2}\right),
$$

где $J$ - число зародышей, возникающих в единицу времени в единицу объема; $\Omega$ - удельный объем, приходящийся на одну частицу в кристалле; предэкспоненциальный член $A$, пропорционален плотности этих частиц в материнской фазе; $k$ - постоянная Больцмана; $\alpha-$ удельная свободная энергия границы кристалл-среда; $\Delta G_{a}-$ свободная энергия активации присоединения новой строительной частицы к зародышу; $\Delta \mu-$ разность химических потенциалов между исходной и конечной фазами. По замечанию Я.Б. Зельдовича приведенное выше соотношение, по-видимому, одна из наиболее силь- ных известных в физике и физической химии функциональных зависимостей, поскольку поверхностная энергия, $\sigma$, входит в степени 3 под знаком экспоненты в числителе, а пересыщение, $\Delta \mu=R T \ln p / p_{0}$ в степени 2 входит в знаменатель.

Хорошо известно, что поверхностная энергия алмаза - одна из наиболее высоких для твердых тел. Однако ее величина многократно снижается при хемосорбции неуглеродных атомов на поверхности. Неравновесная поверхностная энергия при протекании химических реакций на поверхности, может претерпевать дополнительное снижение, что будет рассмотрено в разделе 3. Сильнейшим активирующим зарождение новой фазы, фактором может быть электрический заряд отдельных ионов и дозародышевых кластеров, что лежит в основе действия камер Вильсона. Заряд также может значительно понижать $\Delta G_{a}-$ активационный барьер присоединения новой частицы к зародышу.

\section{3. Гомогенное зарождение алмаза}

В условиях высоковольтного газового разряда в объеме активируемой газовой фазы состоящей из метана и других простейших углеводородов при давлении в единицы Torr [12-14] были получены наночастицы кубического алмаза. Авторы [12] в качестве главного фактора, инициирующего их возникновение, привлекают аналогичное, по их мнению, зарождение частиц конденсированной фазы на треке заряженных частиц в камере Вильсона [12]. Следует также принимать во внимание снижение поверхностной энергии при протекании неравновесной химической реакции [15] и снижение энергии активации при протекании автокаталитической реакции вблизи электрически заряженного центра поверхности [16]. 
При использовании безэлектродного СВЧ-разряда [17] на выходе из зоны плазмы, создаваемой также в субатмосферной газовой смеси из $\mathrm{CH}_{4}, \mathrm{O}_{2}$ и $\mathrm{H}_{2}$, обнаружены как нанокристаллы кубического алмаза (3C-полиморфная модификация), так и нанокристаллы политипов углерода, занимающих промежуточное положение между сфалеритной $(3 C)$ - т.е. обычной алмазной и вюрцитной $(2 H)$ модификациями. Синтезированные частицы малых размеров (десятки $\mathrm{nm}$ ), улавливались специальными фильтрами и исследовались методом микродифракции высоковольтного пучка электронов. Структура частиц была промежуточной между кубической и вюрцитной (лонсдейлит) модификациям, т.е. относилась к политипам алмазного углерода $6 H$, $8 H$ и др. Все это свидетельствует, что зарождение происходило при чрезвычайно высоких пересыщениях, и завершалось образованием неравновесных, по крайней мере, по отношению к кубическому алмазу, кристаллических частиц. Частота их образования в условиях [17] составляла порядка $10^{3} \mathrm{~cm}^{-3} \mathrm{~s}^{-1}$. Остается открытым вопрос, действительно ли в этих и подобных опытах шел процесс гомогенного зарождения, поскольку не следует исключить зарождения алмаза на случайных пылинках, которые могли присутствовать в плазме. Существенно также, что синтезируемые малые частицы могли перегреваться в активируемой газовой фазе. Поэтому температура плазмы не должна быть чрезмерно высокой, т.е. не превышать значительно $1000^{\circ} \mathrm{C}$. При перегреве плазмы выше указанной температуры образование метастабильного алмаза маловероятно, а зарождающийся термодинамически наиболее устойчивый графит должен селективно стравливаться атомарным водородом с образованием углеводородных частиц, возвращающихся в газовую фазу. Поэтому опыты по гомогенному зарождению алмаза следует проводить с использованием сравнительно низкотемпературной неравновесной углеводородводородной плазмы, и только в этом случае можно рассчитывать на достаточно эффективный и управляемый процесс получения алмазных наночастиц в объеме газовой фазы.

\section{4. Гетерогенноое зарождение алмаза на инородных подложках}

Работы, проведенные начиная с шестидесятых годов истекшего столетия в Институте физической химии РАН, показали на примере простейшей химической транспортной реакции $[5,6,10]$ возможность в среде молекулярного, атомарного водорода и углеводородных компонентов переноса углерода с графитового источника $\left(\approx 2000^{\circ} \mathrm{C}\right)$ на алмазную подложку $\left(100^{\circ}\right) \mathrm{C}$ вначале в виде „белой пленки“ (рис. 1), а затем и эпитаксиальных алмазных пленок $[7,8,9]$. В аналогичных условиях обнаружено и самопроизвольное зарождение алмаза на подложках неалмазной природы. На поверхности меди

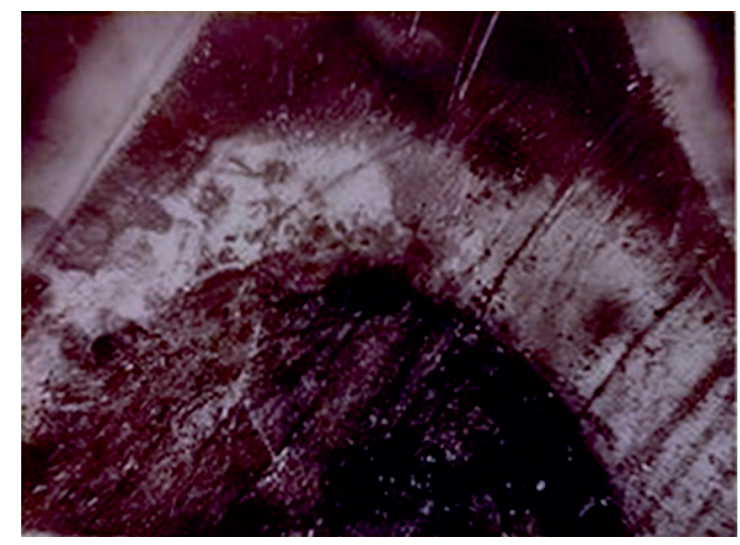

Рис. 1. Первая „белая пленка“, полученная в режиме химической транспортной реакции [5].

(рис. 2) и золота а затем и на карбидообразующих подложках $(\mathrm{Si}, \mathrm{W}, \mathrm{Mo})$, в режиме ХTP наблюдались зарождение и рост микрокристаллов алмаза с характерной кубооктаэдрической огранкой [9]. Скорость зарождения алмаза на неалмазных подложках изменялась от $10^{3}$ до $10^{8} \mathrm{~cm}^{-2} \mathrm{~h}^{-1}$, в зависимости от условий синтеза, материала подложки и ее подготовки: полировка, травление, отжиг.

Уже в первых опытах и последовавших публикациях $[16,17]$ были отмечены следующие закономерности гетерогенного зарождения алмаза.

1) Возникновение алмазных зародышей наблюдалось большей частью на дефектах, таких как царапины и границы зерен.

2) Скорость зарождения алмаза была в несколько раз ниже на монокристалллических подложках в сравнении с поликристаллическими подложками того же вещества.

3) Зарождение алмаза на карбидообразующих подложках $(\mathrm{Si}, \mathrm{W}, \mathrm{Mo})$ происходило на два и более порядка с большей частотой, чем на подложках, не образующих карбиды (медь, золото).

4) По мере протекания процесса зарождения и с увеличением размеров первоначально образовавшихся зародышей частота появления новых зародышей на участках поверхностей, не покрытых алмазом, снижалась.

5) Скорость роста удаленных друг от друга микрокристаллов алмаза была выше, зародышей, растущих при близком расположении друг к другу.

В целом эти закономерности свидетельствовали, что зарождение происходило не в объеме газовой фазы, с последующим захватом гомогенно образовавшихся наноалмазных частиц поверхностью, а непосредственно на поверхности неалмазных подложек в местах, где по различным причинам вероятность их появления была увеличена, т.е. на материалах, имеющих повышенное сродство к углероду, а также на участках их поверхности с геометрической и энергетической неоднородностью. 

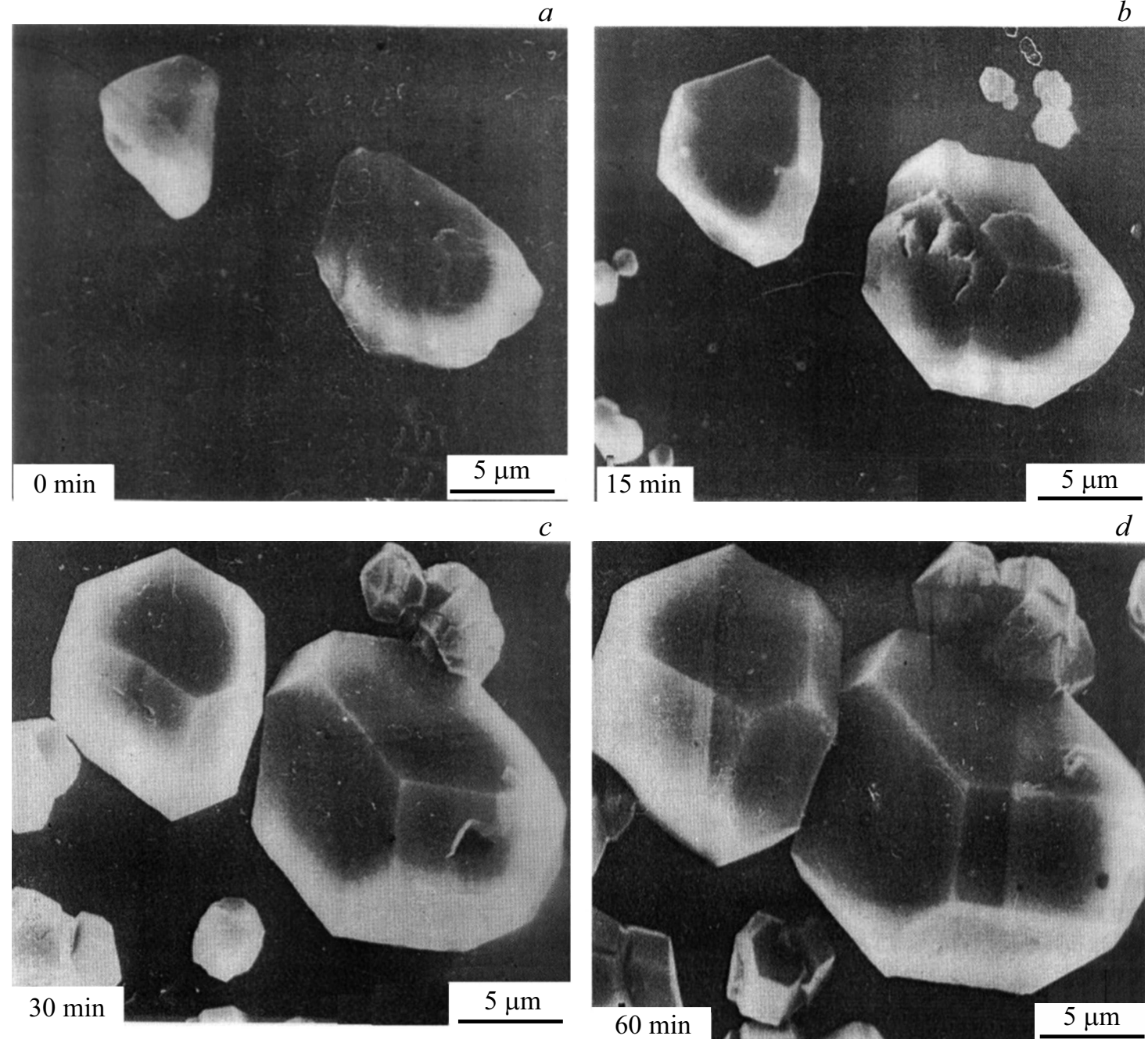

Рис. 2. Начальные стадии наращивания затравочных кристаллов алмаза и спонтанное зарождение центров роста алмаза на поверхности меди в режиме химической транспортной реакции $0,15,30$ и 60 min соответственно [9].

\section{5. Роль геометрии поверхности}

При зарождении алмаза на поверхности карбидообразующих материалах (Mo, W, Si и др.) имеет место

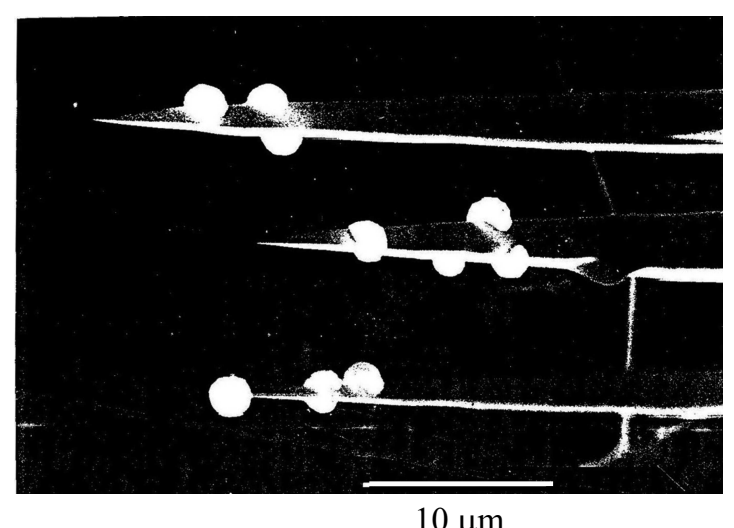

Рис. 3. Наращивание алмазных частиц на нанометровые $\mathrm{Si}$ нитевидные кристаллы. снижение энергии на вновь образуемом участке поверхности между алмазом и неуглеродными атомами подложки. В результате алмазные зародыши образуются преимущественно на острых двугранных углах [20] и даже на вершинах [21] нитевидных кристаллов (рис. 3).

\section{6. Влияние электрического поля на гетерогенное зарождение}

Влияние электрического заряда на интенсивность зарождения алмаза было обнаружено Юго с сотр. [22]. Повышенная частота зарождения на поверхности материалов, граничащих с возбуждаемой СВЧ безэлектродным разрядом газовой фазой наблюдалась ими при концентрации метана $\mathrm{CH}_{4}$ свыше 5\% на относительно гладкой поверхности при электрическом смещении $U_{b}=-70 \mathrm{~V}$. Наибольший эффект был достигнут после $5 \mathrm{~min}$ при концентрации $\mathrm{CH}_{4}$ в газовой фазе $40 \%$ и электрическом смещении $U_{b}=-100 \mathrm{~V}$. Частота зарождения достигала 
$10^{11} \mathrm{~cm}^{-2}$. Последующее наращивание при концентрации $\mathrm{CH}_{4}$ в газовой фазе $1 \%$ при отсутствии электрического смещения обеспечивало образование сплошных нанокристаллических АП толщиной в доли $\mu \mathrm{m}$. Авторы объясняют роль отрицательного смещения повышенной активацией прекурсоров алмаза (или смешанных $s p^{3} / s p^{2}$ состояний кластеров), соударяющихся с поверхностью с повышенной кинетической энергией. Кроме того, наблюдаемый эффект, по крайней мере, частично может быть обусловлен также и повышением поверхностной диффузии.

\section{7. Заключение}

Проведенное рассмотрение процессов зарождения метастабильного алмаза из активируемой газовой фазы позволило обсудить некоторые из наиболее существенных факторов, определяющих, причины снижения поверхностой энергии на поверхности алмазного зародыша, а также инициации и ускорения как гомогенного зарождения под действием электрического поля.

\section{Благодарности}

Автор благодарит Д.И. Галушко за помощь в оформлении публикации.

\section{Конфликт интересов}

Автор заявляет, что у него нет конфликта интересов.

\section{Список литературы}

[1] H.S. Liu, D.S. Dandy. Diamond Chemical Vapor Deposition: Nucleation and Early Growth Stages. Noyes, USA. (1995).

[2] Nucleation Theory and Application / Eds J.W.P. Schmelzer, G. Roepke, V.B. Priezzhevю Dubna: JINR (2002).

[3] П.В. Гордон, С.А. Кукушкин, А.В. Осипов. ФТТ 44, 2079 (2002).

[4] Б.В. Спицын, Б.В. Дерягин. Авт. свид. № 339134 по заявке № 964957/716353 от 10.07.1956 г. на „Способ наращивания граней алмаза“. Опубл. в БИ, № 17. (1980) C. 323.

[5] Б.В. Спицын. Канд. дис. ИФХ АН СССР (1966).

[6] Б.В. Спицын, А.В. Смольянинов. Авт. свид. № 987912. Приоритет 21.04.1971 [Разрешение на публикацию 2013 г.].

[7] Б.В. Дерягин, Л.Л. Буйлов, А.Е. Алексенко, Б.В. Спицын, А.Е. Городецкий, А.П. Захаров, Р.И. Назарова. Докл. АН CCCP 213, 1059 (1973).

[8] B.V. Derjaguin, B.V. Spitsyn, A.E. Gorodetsky, A.P. Zakharov, L.L. Bouilov, A.E. Aleksenko. J. Cryst. Growth 31, 44 (1975).

[9] B.V. Spitsyn, L.L. Builov, B.V. Deryagin. J. Cryst Growth 52, 219 (1981).

[10] Б.В. Спицын, А.Е. Алексенко. Защита металлов 43, 3 (2007).

[11] A.A. Chernov. Ann. Rev. Mater. Sci., 3, 397 (1973).

[12] M. Sokołowski, A. Sokołowska, B. Gokieli, A. Michiski, A. Rusek, Z. Romanowski. J. Cryst. Growth 47, 421 (1979).
[13] Z. Has, S. Mitura. Thin Solid Films 128, 353 (1985).

[14] R. Mania, L. Stobersky, R. Pampuch. Cryst. Res. Technol. 16, 785 (1981).

[15] А.А. Жуховицкий, В.А. Григорян, Е. Михалик. ДАН СССР 155, 392 (1964).

[16] В.Б. Казанский, Н.Д. Чувылкин. Докл. АН СССР 223, 910 (1975).

[17] M. Frenklach, et all. J. Appl. Phys. 66, 395 (1989).

[18] Б.В. Дерягин, Л.Л. Буйлов, А.Е. Городецкий, А.П. Захаров, А.В. Смольянинов. ДАН СССР 231, 333 (1976).

[19] G. Popovici, M.A. Prelas. Phys. Status Solidi A 132, 233 (1992).

[20] P.A. Dennig, D.A. Stevenson. Appl. Phys. Lett. 59, 1562 (1991).

[21] Е.И. Гиваргизов, Е.В. Ракова, В.В. Жирнов, Л.Л. Аксенова, Д.М. Зверев. Докл. РАН. Физика 339, 40 (1994).

[22] S. Yugo, T. Kimura, T. Muto. Vacuum 41, 1364 (1990).

Редактор Д.В. Жуманов 